\title{
PRODUCTIVE WORD FORMATION TENDENCIES IN PRESENT-DAY ENGLISH (based on modern coronavirus vocabulary)
}

\author{
Oksana Torosian, candidate of science in Philology, Institute of Philology, T. Shevchenko Kiev \\ National University, Kyiv, Ukraine, \\ Alina Sheliakina, candidate of science in Philosophy, Institute of Philology, T. Shevchenko Kiev \\ National University, Kyiv, Ukraine,
} DOI: https://doi.org/10.31435/rsglobal_conf/25012021/7358

\begin{abstract}
The given article considers some new word formation tendencies in present-day English forced by the coronavirus pandemic. Changes in productive ways of creating new lexical units are analyzed on the basis of coronavirus vocabulary. Compounding, blending, and abbreviations are among the most frequently used types of present-day word formation that serve to create the words related to the topic given.
\end{abstract}

Keywords: word formation, COVID vocabulary, compounding, blending, acronyms and initialisms.

Introduction. Although productive word formation tendencies in present-day English have been sufficiently studied by linguists, new words constantly appear in the language, so there is a need for their study and detailed consideration of their means of creation. This topic will be relevant as long as the language exists and develops. Lexical changes in contemporary English are still a prolific field of investigation. Examining such changes reveal many trends in the lexicology of English, the types of processes which are observed there, the internal organisation of the vocabulary.

Lexical changes also tell us about the typological options available in the language and how they are used creatively by its speakers. In order to illuminate these various aspects of the subject, the present study considers a representative amount of lexical material which illustrates on-going changes in English lexicology of recent years (2020-2021) influenced by coronavirus pandemic

The material under consideration is part of a corpus of the present-day English usage. It has been gathered over the last year, mostly from sources in the print, spoken, and internet media, as well as from lexicographical sources.

The purpose of the article is to analyze recent trends in English word formation on the basis of COVID vocabulary.

The results of research. The COVID-19 crisis, developing at a rapid pace, makes people extensively use the words and ideas associated with it, and stimulates them to create new words connected with the disease and responses to it.

Usually, such word-formation processes take at least a few years, but there are urgent cases when a new term enters the language and immediately becomes part of our collective regular communication. Such is the case with the language of the present-day pandemic.

Not only new words have appeared, but also some old ones have acquired different denotational and connotative meaning. For example, the word "quarantine" in modern reality is associated with self-quarantine. Some previously used words are now rethought and perceived differently (for example, "distance" used in the collocation "social distance"). What is more, previously, it was a deliberate choice of freelancers to work remotely. Now, this is the only possible way to learn and work (distance learning). Another example includes "lockdown", which was described in the dictionary as "the confinement of prisoners to their cells for all or most of the day as a temporary security measure". Now a new meaning has been fixed: "a temporary condition imposed by governmental authorities (as during the outbreak of an epidemic disease) in which people are required to stay in their homes and refrain from or limit activities outside the home involving public contact (such as dining out or attending large gatherings)".

Taking a word from one context and applying it to another is a significant feature of modern linguistic environment. Some words, which were not so widely known, have become part of everyday vocabulary, for instance, the words "pandemic, coronavirus" and many others were previously used only in medical scientific field. Today every child knows it. 
In his widely cited article on linguistic creativity, Ronald Carter, Professor of modern English language at the University of Nottingham, states that word creativity is challenging the "normal" view of things, and goes on to argue that inventive language is not just decorative, but practical [2].

Recently, we have been made to change our ways of living, businesses and transform our working environment. Consequently, we have got to search for new linguistic inventory to talk about coronavirus-related issues - from the effect the virus has had on our working lives, to the influence of the lockdown methods - or even just a way to cope with the stress around us.

The outburst of metaphors, neologisms and lexical innovations we have seen in the past few months reveals the fact that linguistic creativity is a key part of language, reformatting our ways of cooperating with the world.

Scholars mention different factors influencing present day word formation. Among them there is the internet age, advertising and trademarks, science, entertainment and lifestyles, the globalization of English [1].

Perhaps one of the biggest features in the active spread of coronavirus terminology is the fact that we're more digitally connected than ever before. Instant access social media is now a vital part of our lives - and content is shared with friends and family through a variety of social media channels. The range of our online connections means that there are now far more opportunities for individuals to coin a new term and share it beyond their immediate local communities.

We have analyzed more than 250 words connected with the disease and responses to it $[4,5,6,7,8]$.

Modern English has many ways of forming new words, including affixation, compounding, conversion, blending, clipping, backformation, acronyms, coinage, multiple processes, etc. However, they are not used to the same extent, and the proportion of each of them in the word-formation process is different.

Traditionally, derivation, compounding, and conversion were considered to be the most widespread types of word formation in English. But the analysis of recent words that have entered dictionaries lately demonstrates changes in this linguistic tendency.

Analyzing the recent trends in word formation in English we have come to such results:

- derivation is no longer the prevailing type of creating new words;

- compounding, blending, and abbreviations are among the most frequently used types of present-day word formation;

- there is a big amount of words with multiple word formation process;

- there is a tendency to create a new item with a minimum linguistic resources, on the one hand, and a maximum semantic meaning, on the other hand.

Examples include the following:

\section{- Compounding.}

self-quarantine means to refrain from any contact with other individuals for a period of time,

self-isolate: to isolate or separate oneself or itself from others,

super-spreader and its related noun super-spreading refer to an individual who is highly contagious and capable of transmitting a communicable disease,

doomscrolling, doomsurfing, the limitless need to search the net for new information,

Blursday, an unspecified day because of lockdown's disorientating effect on time,

lockdown/shutdown, more general and extensive restrictions on movement, work, and travel on all people in a city, region, or country. This word is not completely new, but demonstrates a shift of semantic change due to the new reality.

COVID Bubble, open compound word, the social circle you risk exposure for in order to stay sane and have actual conversations with people other than your family. These are friends and family that you see socially on a regular or semi-regular basis, even though none of you really know whether or not you're being entirely safe,

Zoombombing, hijacking a Zoom videocall.

Fears associated with treatments and medical facilities themselves bring us several newly more prominent words:

Iatrophobia: intense fear of doctors,

Nosocomephobia: intense fear of hospitals,

Tomophobia: intense fear of surgery. 


\section{- Blending:}

covidiot, someone ignoring public health advice, covideo party, online parties via Zoom or Skype, covexit, the strategy for exiting lockdown, covidivorce, the divorce caused by forced togetherness as a result of quarantine, coronababies, those who will be born in 2021 , quaranteams, online teams created during lockdown, quaranteens, sometimes called coronials, those who are currently teenagers during a pandemic, zumping, a reference to getting dumped whether by a significant other or your company over Zoom, coronacation, it can be a staycation or working from home forced by pandemic, coronapocalypse, corona apocalypse, coronageddon, corona Armageddon,

quarantine, a mashup of "quarantine" and "martini," this is any cocktail you mix at home while in lockdown. It's a word that also showed up on a lot of restaurants' new takeout menus in places where to-go cocktails became legal,

moronavirus, it's the same virus as the one that starts with a "c," only this is what it's called when covidiots and maskholes test positive. Sometimes used by foreign media to describe what's happening with COVID-19 cases in the United States.

These examples prove a consideration of present-day blends [3] demonstrating that more than one process may be involved. Some words, for example, actually combine different word formation processes: abbreviations, compounding, clipping.

\section{- Acronyms and initialisms:}

COVID-19 is a new name for a new disease, coined as an abbreviated form of coronavirus disease 2019. The name is an odd sort of acronym, insofar as it is formed from portions of two distinct words (COronaVIrus \& Disease) and the latter portion of a date (the 19 from 2019). COVID-19 was first identified in Wuhan, China in December 2019,

$n \mathrm{CoV}$ - novel coronavirus,

$W F H$ - working from home,

$P P E$ - personal protective equipment, COVID-19,

$P U I$ - a person under investigation, or an individual who is suspected of potentially having

$M E R S$ - Middle East respiratory syndrome, an acute infectious disease caused by a coronavirus.

The change of the traditional word-formation patterns exposes the latest tendencies in language, that is striving for the avoidance of long complicated phrases and the need to minimize language resources.

Other traditionally productive types of word formation are represented by infrequent examples.

\section{- Derivation:}

intensivist - a physician who specializes in treating patients who are in intensive care.

\section{- Clipping:}

the rona, coronavirus. It's something you would use, say, after sneezing in front of your neighbors: "Don't worry! It's allergies, not the 'rona!"

Australian English, no stranger to light-hearted abbreviations, has produced 'quaz' for 'quarantine' and "sanny" for "sanitizer".

\section{- Conversion:}

to self-quarantine is "to refrain from any contact with other individuals for a period of time (such as two weeks) during the outbreak of a contagious disease usually by remaining in one's home and limiting contact with family members." [6] The verb is fairly recent, showing evidence of use only within the past 20 years or so. The noun has been in occasional use prior to this in the 20th century.

to zoom - intransitive and transitive verb - to communicate with (a person or group of people) over the internet, typically by video-chatting, using the Zoom.

Conclusions. In times of important social or civil change, linguistic creativity not only reveals the major concerns of the time, but also shows how internal and external forces operate in the vocabulary of a language, how people feel about new challenges and contexts. As coronavirus rages on, understanding the language surrounding it will be ever more important. New words are introduced 
all the time, but few of them enter the wider public consciousness in the way we've seen with coronavirus terminology.

From the results we can make a conclusion that the vocabulary presented has become a practical tool for talking about coronavirus-related issues. The outburst of neologisms and lexical innovations we have already seen for a year shows the ways we cooperate with the world. This new vocabulary also helps people express their worries about the biggest health crisis we have ever seen. Some of the terms presented are new, others have partially changed their meanings, some specialized and technical words often used only by professionals in a given field have been thrown into the general vocabulary. Compounding, blending, and abbreviations are among the most frequently used types of present-day word formation that serve to create the words related to COVID vocabulary.

\section{REFERENCES}

1. Bastian Heynen. Recent trends in English Word-Formation/ https://books.google.ch/books

2. Ronald Carter. Common language: corpus, creativity and cognition/https://journals.sagepub.com/doi/pdf/

3. Thomas Pyles. The origins and development of the English language/ Fort Worth: Harcourt Brace Jovanovich College Publishers, 1993.

4. https://blog.cheapism.com/coronavirus-phrases

5. https://dictionary.cambridge.org/grammar/british-grammar/word-formation

6. https://www.merriam-webster.com

7. https://www.bbc.com/worklife/article/20200522-why-weve-created-new-language-for-coronavirus

8. https://public.oed.com/updates/new-words-list-july-2020/Coronavirus and the New Words We Added to the Dictionary

9. https://www.tmc.edu/news/2020/05/covid-19-crisis-catalog-a-glossary-of-terms/

10. https New Coronavirus Oxford English Dictionary Words 2020 ... 